\title{
A análise da vigilância de Foucault e sua aplicação na sociedade contemporânea: estudo de aspectos da vigilância e sua relação com as novas tecnologias de comunicação
}

\author{
Eugenia Maria Mariano da Rocha Barrichello \\ Doutora; Universidade Federal de Santa Maria \\ eugeniabarichello@gmail.com
}

\section{Elizabeth Huber Moreira}

Mestre; Universidade de Santa Cruz do Sul

liza@viavale.com.br

\section{Resumo}

O presente artigo aborda a análise da vigilância proposta por Michel Foucault. São estudadas algumas caraterísticas da vigilância moderna, as quais o filósofo expõe na sua análise, e, na sequência, estas são pensadas em função da configuração da sociedade contemporânea. Trata-se de uma reflexão teóricoanalítica a respeito das relações entre a vigilância nas sociedades moderna e contemporânea; esta última, definida pela inserção das novas tecnologias de comunicação, entre as quais se destaca a internet.

\section{Palavras-chave}

Vigilância. Foucault. Tecnologias de comunicação.

\section{Introdução}

Na década de 1970, Michel Foucault elaborou sua análise sobre a sociedade da vigilância. Desde então, a comunidade acadêmica tem se voltado, com maior ou menor interesse, para as questões que envolvem a vigilância e o uso do poder para fins de controle dos indivíduos. Nos dias atuais, especialmente a partir da divulgação pela imprensa, no mês 
de junho de 2013, da vigilância realizada pelo governo americano nas comunicações de cidadãos comuns, políticos e empresários ao redor do mundo ${ }^{1}$, o tema voltou à cena e passou a ser debatido por especialistas de diversas áreas - entre elas a Ciência da Informação, o Direito e a Comunicação. 0 tema da vigilância voltou a levantar questões e a ser confrontado com aspectos fundamentais da vida em sociedade, como a segurança nacional e a privacidade.

Qualquer que seja a posição que o indivíduo ocupe na sociedade - seja a de cidadão comum, a de presidente de uma companhia privada ou a de homem público -, ele pode estar sendo vigiado. Os rastros que este indivíduo deixa ao realizar compras pela internet, ao trocar mensagens com amigos pelas redes sociais ou ao visitar sites e blogs, por exemplo, podem ser capturados, armazenados e utilizados conforme a conveniência de quem exerce esta vigilância. Os que fazem uso deste poder, geralmente, são grupos que representam os interesses de governos ou de organizações da iniciativa privada.

A vigilância sobre o comportamento dos indivíduos e das populações é considerada por Foucault (1996) como uma questão epistemológica e que merece estudo de suas manifestações a partir da Idade Moderna, que se inicia no final do século XVIII e se estende até meados do século XX. É neste cenário que o poder passa a assumir determinadas configurações, as quais fazem da vigilância hierárquica um dos seus principais instrumentos. Segundo Foucault (1996), ela passa a ser fundamental para o exercício do poder moderno, junto com a sanção normalizadora e o exame.

A vigilância permite a produção de conhecimento sobre aqueles que são vigiados aspecto fundamental para o exercício do poder. Nesse contexto, poder e saber são coadunados de forma a propiciar um controle ainda mais contundente, perene e profundo. Vigiar viabiliza a produção do saber e torna possível conhecer o objeto que está sob vigilância, uma vez que o saber produzido reforça as possibilidades de exercer poder sobre tal objeto.

Sem a pretensão de esgotar o tema, o objetivo deste artigo é salientar determinados aspectos da análise da vigilância realizada por Foucault (1996) e utilizá-los no estudo de fenômenos atuais propiciados pelas novas tecnologias de informação e de comunicação. Cada vez mais, as pessoas usam as novas tecnologias para se comunicar e se relacionar com

\footnotetext{
${ }^{1} 0$ jornal britânico The Guardian e o americano Washington Post denunciaram que as autoridades federais americanas haviam tido acesso aos registros telefônicos de milhões de clientes da Verizon Communications e que teriam utilizado, com fins de vigilância, os serviços de empresas como Google, Microsoft, Apple e Facebook para acessar e-mails, fotos e arquivos de usuários a fim de rastrear seus movimentos e monitorar seus contatos (SPETALNICK; HOLLAND, 2013).
} 
outras pessoas, comprar, vender, estudar e buscar informação. 0 uso da internet para estas atividades já pode ser considerado corriqueiro e não é mais uma novidade. Porém, se por um lado a utilização da rede mundial de computadores para estas tarefas facilita a sua realização, por outro traz uma possibilidade concreta de que as ações e as comunicações de quem a usa sejam vistas e vigiadas por aqueles que controlam tal atividade. Parece oportuno, portanto, refletir sobre a questão da vigilância e de sua prática na sociedade contemporânea, a fim de compreender como os mecanismos de vigilância agem e produzem saber na atualidade.

A sociedade atual difere, em certa medida, da sociedade moderna que serviu de modelo para as proposições de Foucault (1996) sobre a vigilância e o exercício do poder. Uma das principais transformações ocorreu a partir do surgimento das novas tecnologias de comunicação, com o advento da internet. Contudo, é possível inferir que as colocações feitas pelo filósofo podem ser perfeitamente utilizadas para a análise dos fenômenos contemporâneos, que envolvem o uso dessas tecnologias como forma de exercício de um poder controlador e de uma vigilância que se aplicam, atualmente, de forma ainda mais efetiva e onipresente.

\section{Foucault e a análise da vigilância}

Na obra Vigiar e punir (1996), o filósofo e epistemólogo francês Michel Foucault apresenta a sua análise sobre a sociedade da vigilância. Em contraposição ao Absolutismo, período histórico antecessor da Modernidade, Foucault (1996) salienta as características da sociedade moderna, a qual ele chama de disciplinar, e diz que um dos instrumentos do qual esta se vale é o olhar hierárquico. Junto à sanção normalizadora e ao exame, o aspecto hierárquico forma a tríade basilar do exercício de um poder que busca produzir saber a respeito dos vigiados e adestrar os seus comportamentos.

Este olhar que vigia tem determinadas características que permitem o seu uso efetivo. Estas particularidades serão analisadas neste artigo e pensadas com relação à forma como se dá a vigilância nos dias atuais. Em primeiro lugar, trata-se de um olhar que vê sem ser $v_{i s t o}$; a luz deve ser projetada sobre o objeto que está sendo vigiado, enquanto aquele que vigia tende a se tornar invisível. E quanto mais invisível ele se torna, mais definitiva e

\footnotetext{
2 As características apresentadas por Foucault (1996) sobre a vigilância estão, neste artigo, grifadas em itálico para facilitar a sua visualização e posterior análise com relação ao exercício do poder na sociedade contemporânea.
} 
permanente passa a ser a sua capacidade de vigiar. No entanto, a sua presença é sempre sentida, trata-se de uma onipresença, de uma ubiquidade do poder que não permite escape e que não supõe um momento ou um lugar sem vigilância. $O$ homem moderno está sempre se sentindo vigiado, vive em espaços projetados para este fim. Mas a real presença daquele que vigia nem sempre é notada, ela não se dá a perceber justamente para potencializar a vigilância. E, assim, é uma presença pressentida, sempre tomada como real, apesar de nem sempre poder ser verificada.

Além disso, o olhar opera por meio de "vigilâncias múltiplas e entrecruzadas" (FOUCAULT, 1996, p. 154), das quais é difícil escapar. São muitas as formas e os momentos de vigilância e são inúmeros os registros feitos a respeito dos comportamentos. Para formar um saber sobre o outro é necessário estabelecer um método de registro do comportamento, que permita a sua análise e o uso efetivo das informações registradas. Surgem os prontuários médicos, os registros de internamento, os relatórios dos processos judiciais, as tabelas de controle da produção nas fábricas e as cartilhas de pedagogia escolar.

Para melhor conhecer é preciso bem vigiar, e a efetividade da vigilância depende do entrecruzamento de formas de vigilância e de informações. Assim, forma-se um saber sobre o outro. Nesse sentido, a vigilância deve ser hierarquizada, ou seja, ela depende da formação de uma hierarquia entre os indivíduos, que permite definir quem vigia quem, como e quando, de tal forma que poucos podem vigiar muitos. Foucault $(1996$, p. 156) fala sobre um modelo piramidal que permite "[...] formar uma rede sem lacuna - possibilidade em consequência de multiplicar seus degraus, e de espalhá-los sobre toda a superfície a controlar; e, entretanto ser bastante discreta para não pesar como uma massa inerte sobre a atividade a disciplinar".

Somam-se a esta questão as estruturas arquiteturais que permitem a disposição dos indivíduos no território, de forma a propiciar o exercício da vigilância. A suntuosidade dos palácios do Absolutismo, feitos para serem admirados, dá lugar a uma arquitetura que não é construída para ser vista, antes é projetada para tornar mais fácil ver aqueles que se encontram no seu interior.

Foucault (1996) cita o panóptico, modelo arquitetural sugerido por Jeremy Bentham, no final do século XVIII, como o ideal para as prisões. Trata-se de uma torre central que permite ver todas as celas dispostas ao seu redor; porém, a presença de alguém na torre não é possível de ser percebida pelos indivíduos que estão nas celas. É impossível saber se há alguém na torre vigiando ou não. A vigilância torna-se, portanto, contínua, pela 
impossibilidade de ser detectada. O panoptismo, para Foucault (1996), pode ser traduzido na interiorização do olhar daquele que vigia a tal ponto que o indivíduo passa a se vigiar, não há mais necessidade de outra pessoa em tal tarefa. É o nível mais alto da vigilância, quando o indivíduo vigia a si mesmo e não se permite agir fora das regras que introjetou.

Segundo Foucault a vigilância se estabelece como uma

[...] rede de relações de alto a baixo, mas também até um certo ponto de baixo para cima e lateralmente; essa rede 'sustenta' o conjunto e o perpassa de efeitos de poder que se apoiam uns sobre os outros: fiscais perpetuamente fiscalizados. (FOUCAULT, 1996, p. 158).

Muitas questões aqui são merecedoras de comentários. Para Foucault (1988), o poder se exerce por meio de relações entre pessoas, que são sempre desiguais e móveis. 0 poder é uma estratégia para alcançar um objetivo, não um objeto que pode pertencer a alguém, muito menos um lugar a ser ocupado e cobiçado. 0 que existe são relações de poder e não este em si mesmo. Além disso, o poder disciplinar “[...] está em toda parte e sempre alerta, pois em princípio não deixa nenhuma parte às escuras e controla continuamente os mesmos que estão encarregados de controlar". (FOUCAULT, 1996, p. 158). Como numa rede, todos vigiam todos e reforçam a vigilância.

São imprescindíveis para a vigilância na Modernidade as instituições sociais - entre as quais se destacam a escola, a fábrica, o asilo e a prisão -, lugares esses que mesclam poder e saber e que contribuem para o exercício de um poder controlador e adestrador de comportamentos. Segundo Lechte (2002, p. 133), a forma como o poder moderno é exercido é resultado das "[...] mudanças engendradas pela emergência de instituições que lidam com a formação de conhecimento sobre os indivíduos. 0 conhecimento é, portanto, ligado ao poder". Saber e poder são indissociáveis e são alimentados pelo mesmo instrumento: a vigilância hierárquica.

Além disso, Lechte (2002, p. 133) diz que para Foucault "O poder é dispersado por toda a sociedade (ele não é possuído por ninguém) e tem efeitos positivos". Quando o poder e o saber se articulam e geram conhecimento e discurso sobre o seu objeto, atuam de forma produtiva e não apenas proibitiva, o que pode ser considerado como algo positivo. 0 saber gera poder, mas o poder também gera saber.

Trata-se de uma vigilância absolutamente discreta, que "[...] funciona permanentemente e em grande parte em silêncio". (FOUCAULT, 1996, p. 158). A vigilância hierárquica opera de forma contínua, uma vez que os espaços onde os indivíduos vivem e estabelecem suas relações pessoais e de trabalho - as instituições sociais - são projetados 
para promover esta vigilância permanente e ininterrupta. Os desenhos das fábricas e das prisões, por exemplo, são feitos para aperfeiçoar funcionalmente esta vigilância permanente e ubíqua. Ela é silenciosa e discreta, porque não mais se apresenta de forma faustosa, com o brilho e a suntuosidade que se dava no Absolutismo. Não há mais o destaque do soberano. Os que vigiam devem ficar ocultos e discretos, quem deve ser visto é o objeto do exercício do poder, até porque o objetivo é analisar, estudar e conhecer - formar saber - e, para isto, é preciso observar. É necessário que haja espaços e maneiras de olhar sem ser visto, para depreender o conhecimento sobre o outro da forma mais plena possível.

O poder exercido pela vigilância hierárquica funciona como uma máquina, não como um objeto que alguém possa possuir ou arrebatar para si. Não se transfere como uma propriedade. Antes, ele funciona em relações de poder que são móveis e que operam como uma engrenagem, cada parte só reage em função da ação da outra. 0 poder moderno é um exercício articulado, operado pela intencionalidade. É um jogo de estratégias, mesmo na resistência - que seria o seu outro lado - há poder.

As técnicas de vigilância permitem o exercício de um poder que articula o domínio sobre o corpo sem o uso da violência, uma vez que o objetivo não é ferir nem marcar aquele a quem o poder se aplica, e sim adestrar comportamentos. Para alcançar este objetivo, toda uma engenharia da vigilância se consubstancia em dispositivos de exercício de um poder que visa o controle dos comportamentos e das ações: estruturas arquitetônicas, discursos, regras, práticas, instituições, táticas, enunciados científicos e proposições morais.

$\mathrm{Na}$ atualidade, com o advento das tecnologias de informação e comunicação digitais, o exercício do poder a partir desses dispositivos sofre, de certa forma, uma alteração na sua composição. Somam-se às formas de vigilância modernas outras que prescindem da presença física entre quem vigia e quem é vigiado.

A proposta, na parte seguinte do texto, é entender como os postulados de Foucault sobre a vigilância moderna, apresentados até aqui, podem servir de roteiro para a análise dos fenômenos atuais de vigilância propiciados pelas novas tecnologias.

\section{A vigilância e as novas tecnologias de comunicação}

Na edição do telejornal Bom Dia Brasil3, que foi ao ar no dia 17 de dezembro de 2013, três notícias abordaram a questão da vigilância. A primeira trata sobre câmeras de vídeo

3 Telejornal matutino da Rede Globo, transmitido em canal aberto. 
instaladas em escolas brasileiras para diminuir a violência. A segunda e a terceira abordam o caso de espionagem revelado por Edward Snowden ${ }^{4}$, em junho do mesmo ano.

Considerando o que foi veiculado, a segunda notícia traz a informação de que um juiz federal, dos Estados Unidos, declarou ilegal a espionagem, mas advertiu que se o ato tiver sido realizado com a finalidade de garantir a segurança nacional, a sua posição a respeito do caso poderá ser revista. A terceira revela que Snowden pediu asilo ao Brasil (no momento ele está em asilo temporário na Rússia). Caso consiga asilo em nosso país, prometeu colaborar com mais informações sobre as investigações feitas no Brasil pelo governo americano, sobre a presidente Dilma Rousseff e sobre a Petrobras.

Trata-se de três matérias sobre o tema da vigilância veiculadas numa mesma edição de um telejornal. Duas delas abordam a vigilância digital. É inegável que, desde as denúncias feitas por Snowden, a questão voltou a ser um tema de debate e que mobiliza os interesses públicos. É patente que, cada vez mais, a vigilância tem sido realizada com o auxílio da internet.

Segundo Bruno (2008, p. 169), a vigilância digital é o “[...] monitoramento sistemático, automatizado e a distância de ações e informações de indivíduos no ciberespaço, com o fim de conhecer e intervir nas suas condutas ou escolhas possíveis". É o monitoramento das ações realizadas pelo indivíduo no ciberespaço, a partir dos rastros deixados pela ação por ele realizada. Nesse contexto, as informações são coletadas e armazenadas em bancos de dados (BRUNO, 2006). A vigilância digital pressupõe, portanto, o recolhimento das informações de usuários da internet e o armazenamento de tais dados para futura utilização, a fim de conhecer e controlar as atitudes ou preferências dos vigiados. Pelo fato de ser realizada por meio de dispositivos digitais, pode ocorrer de forma contínua e automática. Outra característica é que a presença física, entre quem vigia e quem é vigiado, não se faz mais necessária.

Ainda segundo Bruno (2006, p. 154), “[...] o dispositivo de vigilância digital tem três elementos centrais: a informação, os bancos de dados e os perfis computacionais (profiles)". A informação é a matéria-prima, é sobre ela que se dá a vigilância. Os bancos de dados permitem registar a informação, a qual pode ser, então, acessada quando necessário. Os perfis computacionais viabilizam gerar conhecimento a partir dos dados e atuam nos "[...] procedimentos de individualização e produção de identidades". (BRUNO, 2008, p. 170).

\footnotetext{
${ }^{4}$ Snowden - ex-analista da Agência de Segurança Nacional dos Estados Unidos (National Security Agency - NSA) - foi o autor das denúncias sobre espionagem que a NSA teria realizado em registros telefônicos de clientes da Verizon Communications e de e-mails e arquivos de usuários de empresas como Google, Microsoft, Apple e Facebook.
} 
Pode-se perceber, pelo que foi exposto até o momento, que existem proximidades evidentes, mas também diferenças significativas, entre o pensamento de Foucault (1996) sobre a vigilância moderna e as formas de vigilância digital que atuam na sociedade contemporânea. Com relação à característica da vigilância como um olhar que vê sem ser visto, pode-se dizer que a digital também opera da mesma forma. Aquele que vigia pretende não ser visto nem percebido. Se pensarmos que hoje o poder busca menos adestrar comportamentos do que prever tendências (BRUNO, 2006), faz sentido em haver uma vigilância não percebida. Quanto menos ela for notada como algo existente dentro do próprio sistema de comunicação digital, mais autenticidade haverá nas informações que poderão ser coletadas. Não ser visto é uma estratégia que garante a autenticidade do conteúdo informacional colhido. 0 fato de não demandar presença física também contribui para que a vigilância passe despercebida.

Todas as comunicações realizadas por meio digital, especialmente com a utilização dos grandes controladores de sites de comunicação e de relacionamento, estão passíveis de serem coletadas e armazenadas. Quem detém a tecnologia possui também o poder sobre ela e sobre as operações realizadas por meio dela. 0 usuário nem sempre percebe, mas a possibilidade da vigilância ocorrer é real.

Destaca-se que a vigilância digital também opera por meio de vigilâncias múltiplas e entrecruzadas. Os usuários de internet geralmente se valem dos serviços de duas ou mais empresas que controlam o mercado de comunicação, ao fazerem uso dos serviços de telefonia móvel, mensagens eletrônicas, sites de redes sociais, compartilhamento de fotos e vídeos. As informações coletadas, se forem de interesse dos governos (por questões de segurança nacional) ou das companhias privadas (por interesse mercadológico), podem ser correlacionadas e gerar o que Bruno (2006) chama de perfis computacionais. Estes perfis permitem a elaboração de um saber sobre o outro, nos termos do que foi proposto por Foucault (1996).

Para Fuchs,

[...] na sociedade contemporânea, as tabelas assumem a forma de bases de dados digitais que guardam grande quantidade de dados que podem ser automaticamente coletados, acessados, manipulados e remixados, estão disponíveis em tempo real, são distribuídos em alta velocidade por todo o mundo, são fáceis e baratos de coletar e distribuir, e podem ser duplicados sem destruir o dado original. As bases de dados no computador permitem uma extensão e uma intensificação da vigilância baseada em tabelas. (FUCHS, 2011, p. 117). 
Para gerar um saber sobre o outro é necessário registrar e analisar seu comportamento, conforme revela Foucault (1996) sobre o poder moderno. Na vigilância digital, para gerar saber é necessário registrar e analisar suas ações e comunicações na internet. Fuchs (2011, p. 118) revela que, na sua percepção, “[...] a conexão poder/saber que Foucault ressalta como constitutiva para a vigilância assume a forma poder/dados digitais na era da informação". São estes dados digitais que contêm as informações necessárias para se gerar o saber sobre o outro.

E, mais uma vez, poucos podem vigiar muitos. Poucas são as companhias que detêm o controle sobre as comunicações digitais realizadas por milhões de usuários. Essas empresas detêm o poder do acesso à informação. As informações coletadas, por sua vez, são efetivamente usadas pelos governos e por companhias da iniciativa privada, que também representam um contingente pouco numeroso, a receber os dados de um grande número de pessoas.

Quanto às estruturas arquiteturais, a vigilância digital faz uso da própria arquitetura da rede que, por ela mesma, favorece a vigilância. Todas as informações passam por servidores, que são os nós da rede. Entre o emissor e o receptor da informação, a mensagem eletrônica encontra vários nós. Em cada um deles ela pode ser interceptada, coletada e armazenada.

Com relação à vigilância se estabelecer como uma rede de relações que atua de modo que todos possam vigiar todos e, dessa forma, reforçar a vigilância, é preciso ponderar que, no caso da vigilância digital, é necessário dominar as tecnologias de acesso à informação. Essa prática é "[...] menos sobre corpos do que sobre dados e rastros deixados no ciberespaço". (BRUNO, 2006, p. 153) e não é mais realizada com o olhar. Este é substituído pela coleta, registro e classificação da informação (BRUNO, 2006) e, portanto, é preciso dominar a tecnologia que possibilita essas ações. Desta forma, não é mais possível todos vigiarem todos. Na sociedade contemporânea, poucos vigiam muitos.

Ainda temos uma vigilância absolutamente discreta, que precisa não ser detectada para funcionar adequadamente. Ela não se faz perceptível. Para Bruno (2006, p. 154), “A vigilância se confunde hoje com a própria paisagem do ciberespaço". Ela atua por meio dos próprios mecanismos que viabilizam a sua utilização pelos usuários. Usando a internet é que os indivíduos geram informação e deixam rastros passíveis de serem vigiados. A tecnologia que permite enviar mensagens e postar fotos e vídeos é, ela mesma, usada para interceptar 
o conteúdo e exercer a vigilância. Portanto, a discrição é inerente ao processo de vigilância digital.

Por fim, a vigilância digital também funciona como uma máquina, assim como a vigilância hierárquica moderna, mas não em função da intencionalidade ou da resistência, e, sim, porque funciona como uma engrenagem. Ela depende das pessoas que são vigiadas, pois precisa que elas usem as tecnologias, que deixem seus rastros. Um hemisfério move o outro. Se os usuários não usarem a rede, inviabilizam a vigilância digital.

\section{Considerações finais}

As novas tecnologias de informação e de comunicação que surgem na sociedade contemporânea, em especial a internet, trazem novas possibilidades e experiências de vigilância, uma vez que esta não se dá mais somente por meio do olhar e da presença física entre quem vigia e quem é vigiado. A comunicação, a partir de uma rede mundial de computadores, possibilita uma nova forma de vigilância que opera através do registro dos rastros deixados pelo indivíduo no ambiente digital. A vigilância não é mais sobre comportamentos e sim sobre ações e comunicações via internet.

0 poder hoje não busca mais adestrar comportamentos. Pode-se, inclusive, afirmar que, atualmente, as formas de se comportar não assumem mais um papel tão importante e significativo como assumiam na sociedade moderna. Mas, o poder ainda busca produzir saber e a produção de saber ainda se dá pela vigilância, não mais de comportamentos, mas de ações e comunicações digitais.

A vigilância digital, assim como a moderna, ainda atua de forma discreta, para que não seja percebida. Não se fazer notar é uma condição indispensável para a efetividade do processo. Talvez, seja por esta razão que os usuários das tecnologias de comunicação não tomam conhecimento de que, no uso cotidiano de tais ferramentas e plataformas, deixam rastros ao operarem na internet e que estes rastros podem ser coletados, armazenados e utilizados pelos governos e empresas privadas, se for o caso. 0 uso tão naturalizado das novas tecnologias por parte dos usuários e a absoluta discrição com que a vigilância atua contribuem para que o fato de que terem seus dados e informações vigiados não seja percebido pelos indivíduos.

Continuamos, ainda, a viver numa sociedade da vigilância. Hoje, ela apresenta novas características, atua num ambiente digital e se dá sobre as comunicações. Os propósitos são 
outros, assim como os processos, porém, o fato é que, tal como ocorria na sociedade moderna, na contemporânea a vigilância também opera em benefício do exercício de um poder controlador.

\section{Referências}

BRUNO, Fernanda. Dispositivos de vigilância no ciberespaço: duplos digitais e identidades simuladas. Revista Fronteiras, São Leopoldo, v. 8, n. 2, p. 152-159, maio/ago. 2006.

BRUNO, Fernanda. Monitoramento, classificação e controle nos dispositivos de vigilância digital. In: ANTOUN, Henrique (Org.). Web 2.0: participação e vigilância na era da comunicação distribuída. Rio de Janeiro: Mauad X, 2008. p. 167-182.

FOUCAULT, Michel. História da sexualidade I: a vontade de saber. Rio de Janeiro: Graal, 1988.

FOUCAULT, Michel. Vigiar e punir: nascimento da prisão. 14. ed. Petrópolis: Vozes, 1996.

FUCHS, Christian. Como podemos definir vigilância? Matrizes, São Paulo, v. 5, n. 1, p. 109136, jul./dez. 2011.

LECHTE, John. Pensamento pós-estruturalista. In: . Cinquenta pensadores

contemporâneos essenciais: do estruturalismo à pós-modernidade. Tradução: Fábio Fernandes. Rio de Janeiro: DIFEL, 2002. p. 129-134.

SPETALNICK, Matt; HOLLAND, Steve. Obama defende com firmeza programas de vigilância do governo dos EUA. Reuters Brasil. 2013. Disponível em:

<http://br.reuters.com/article/worldNews/idBRSPE95605V20130607>. Acesso em: 8 jun. 2013. 


\title{
Foucault's analisys of surveillance and its application in the contemporary society: studing aspects of surveillance and its relation to new communication technologies
}

\begin{abstract}
The present article discusses the analisys of surveillance proposed by Michel Foucault. Some features of modern surveillance exposed by the philosopher are analyzed and subsequently, thought regarding the configuration of contemporary society. It is a theoretical-analytical reflection on the relations between surveillance in modern society and contemporary society, which is defined by the insertion of new communication technologies, highlighting the internet.
\end{abstract}

\section{Keywords}

Surveillance. Foucault. Communication technologies.

Recebido em 06/09/2014

Aceito em 22/04/2015 